E3S Web of Conferences 2, 03007 (2014)

DOI: $10.1051 /$ e3sconf/ 20140203007

(C) Owned by the authors, published by EDP Sciences, 2014

\title{
VELUXlab: a sustainable prototype of active house for innovation
}

Marco Imperadori ${ }^{\mathrm{a}}$

A.B.C. Department, Politecnico di Milano, Italy

\begin{abstract}
Active House is a vision of buildings that create healthier and more comfortable lives for their occupants without impacting negatively on the climate. The concept is based on a responsive behavior of the building, capable to answer instantly to the climate strains changing automatically its configurations and assuring the indoor comfort and energy saving. Active House Alliance is the no-profit organization that is working on this definition and Politecnico di Milano, as member, is developing a solution for the adaptation to the south Europe, where the climate and the weather stress are different. VELUXlab is the first prototype of this vision in Italy. It is the first Italian NZEB in a university campus and, soon, it will be certified also as the first Italian Active House. The wireless sensor network system allows to control in real time the duo envelope (multi-layer dry construction) and automation technology performances, strengthening the good results obtained from the virtual dynamic simulations made during the design process.
\end{abstract}

\section{New buildings for sustainable architecture}

The energy problem linked to the building sector has been for years item of researches: the aim is to find new way of design and to reflecting it into laws and regulations that could lead to a sustainable living. In the last years, we have been witness of the innovation of the building sector, that it is trying to improve buildings behaviour in order to save energy and optimize the use of renewable sources. Reducing the waste of energy is the most important goal of every new vision and, considering that buildings consume more than $40 \%$ of all the energy we use and about $50 \%$ of it is used for the conditioning systems, it is easy to understand why. The recast of the Energy Performance of Buildings Directive (EPBD) defines a new category for construction: the nearly zero energy buildings; a NZEB is a building with a very high performance and a very low amount of energy required that should be covered by energy from renewable sources produced on-site or nearby. This definition is clear: it does not mean buildings without energy demand at all, but smart buildings capable to meet their needs from low cost, locally available and renewable sources, Pless and Torcellini (2010). However accounting the energy balance with the grid is necessary in order to compensate to the unpredictability of the on site generation with renewable sources, because of the strong connection with weather, climate and other variables. Interaction with an existing energy infrastructure is the key for balancing the energy supply and demand. Achieving NZEB is possible only through a simple two step concept: first reducing the demand and then exporting energy optimally into external grids, Voss at al (2011).

${ }^{\text {a } C o r r e s p o n d i n g ~ a u t h o r: ~ m a r c o . i m p e r a d o r i @ p o l i m i . i t ~}$ 
Without the grid is quite impossible to realize a NZEB: storage technologies at the current generation are limited and the benefits could be less than the costs. Off-grids buildings must satisfy the demand with local sources even when the conditions are not favourable and also manage the time gap between the peaks of production and demand: without the possibilities of using the grid as energy storage it is necessary to oversized the energy production systems; Torcellini et al (2006). The most evident examples is the electricity needed for the commercial sector: it is doubled between 1980 and 2000 and it is expected to increase $50 \%$ by 2050 , EIA (2005). It is clear that renewable sources, such as PV systems, are needed to cover this demand but, at the same time, the grid is necessary to compensate for the time lag between the peak of production (summer) and of the need (winter). The use of the grid could also be useful in another way: as an exchanger. The NZEB definitions and classifications enable renewable energy generation to offset various fossil fuel energy uses, the offset level is determined by the energy use accounting method, allowing a building to produce more than it is needed for its use and exchange it with energy from non-renewable sources. This exchange is led by a source-to-site ratio, depending on the type of NZEB and on the utility mix, documented by Deru et al (2006). This is the key point on which was borne the idea of Active House: taking the energy surplus produced by renewable sources in count and not only in consideration for energy exchange credits. The innovative side of the vision is the consideration of all the production into the energy balance and not only the part necessary to matching the annual needs.

\section{Active House}

"Active House is a vision of buildings that create healthier and more comfortable lives for their occupants without impacting negatively on the climate. The world is facing several environment challenges: traditional resources are scares and global warming is worrying more and more our future. Meanwhile there is a strong need to meet essential human needs for an healthy and comfortable indoor climate. Active House Alliance is trying to respond to these factors: the vision represents the next generation of sustainable buildings that take in count energy and comfort" (Active House Specification, 2011). The Active House Alliance is a non-profit organization supported by a group of partners with the same ambition: create an independent and international vision of buildings and define a long term goals for the future building stock. Active House isnot only residential, but it is a target framework for how to design buildings that can contribute positively to the environment, assuring indoor comfort and sustainability. It is every kind of construction: new-build or renovation, homes or offices and the purpose of the Alliance is to spread a new balanced and holistic approach to the construction sector. Three are the main aspects on which it is based the Active House Specification: energy, environment and indoor climate. The integration and the harmony between them is key point for achieving the purpose. Focusing carefully on these principle it is clear what it is expected from an Active House. The label "energy" is strictly connected to the efficiency of the building: the energy balance must be positive and renewable source should be integrated in the architecture and capable to supplied all the needs. On site generation, as in the NZEB standard, is a key point: all the energy should come from the footprint of the building or, at least, from the nearby collective system. The comfort and the sense of well-being are the main aspects of the category "indoor environment": the building should ensure good indoor air quality, adequate thermal climate, appropriate visual and acoustical healthiness for the occupants. However it is necessary also to have a control and automated system easy to use, in order to encourage responsible environmental behaviour, changing the way of living and the awareness about the sustainability. "Environment" is the third point of the vision: minimizing the building's impact is the aim of the design process. The only way for reaching this results is through an optimized relationship with the local context: materials should have high recyclable content and should provide the ability for its own recycling or re-use. Thanks to the Specification it is possible to quantify these labels through a set of tangible values: the calculating procedure is described clearly, indicating the performance requested and the evaluation table in order to know the specific result reached. The parameters taken under consideration to evaluate an active house and the interaction between them is then represented on a simple tool: the Active House Radar, 
that makes possible to visualize the general performance of the building. It is also reasonable to use it for a preliminary study about the building and the context, in order to understand which parameter should be pushed more for having the best efficiency of the building itself. The value of the design process is represented by the integration of different aspects in order to promote quality in terms of architecture, comfort and efficiency.

\section{Politecnico di Milano and research}

Politecnico di Milano is actively involved in the studies about the new Specification as member of the Active House Alliance. The research is focused on the adaptation of the AHS to the southern European regions and the aim is to understand deeply the interaction between the building and the weather. This is an important step in the definition of the new features of Active House, because it would allow to enlarge the value of the AHS to a different variety of climate and external conditions. This is a necessary step, thinking that the specification has been developed using an open-source model, involving online debates and contributions as well as offline meetings and workshops with broad participation across the building industry. This process uses a mixed method approach that consider the vision as a starting point and then is implemented with the empiric results of the cases study; so it is clear that the outcome is strongly connected to the range of buildings analysed. The Alliance was born in the North Europe and, until Politecnico di Milano joined it, all the centres of research partners were from this regions. It is easy to understand why the Active House Specification fits perfectly to the cold weather regions, but there is still a caution about the southern Europe. Politecnico di Milano is testing and studying the theme through the analysis of the energy and comfort behaviour of the first Italian built construction certified as Active House: VELUXlab. Improving the envelope and assuring the internal comfort are two aspects of the proposed vision, and ,of course, the connection with temperature, humidity and solar radiation is the essential point for creating a synergy between these sides. The aim of the research is to adapt the evaluation scheme even to hot and warm climate, where the weather stresses are different and more complex.

\subsection{VELUXIab}

VELUXlab is a new centre of research for Politecnico di Milano, placed in Bovisa Campus, it is the first Italian nearly zero energy building in a university campus and the first Italian built Active House. It is the renovation of the model home for Mediterranean climate Atika, designed by J.A.Cantalejo and A.Ronda from ACXT/IDOM studio for Velux, made by Atelier2 studio and experts from Politecnico itself. The design was led by dynamic analysis on the behaviour of the building in different possible situations, in order to understand better the real working conditions in order to optimize the resources. The attention to the energy saving is visible in the shape itself: it is calibrated to maximize the solar gains in winter and the shadows in summer, preventing overheating and assuring, with the insulated shell, a thermal shield to the indoor rooms. The materials are all innovative but recycled or recyclable, as the label 'environment' of the AHS suggests. Everything is re-taken from the previous destination or from the waste of the construction's processing: for example the space of the sub-structure of the façade is filled with insulating powdered material of the building site. The main innovative feature is the attention on the indoor climate: healthy and comfortable spaces in order to assuring the maximum target for these parameters in the AHS. Insulation makes the envelope air thigh and really performing in keeping the temperature stable, internal cladding helps in cleaning the air and maintaining the atmosphere safe for the occupants. The ceiling, in fact, is made with gypsum and zeolite panels, capable to clean the air from the polluting dust. The building is designed to answer instantly to the climate change and to reach naturally the indoor comfort for the users, only in the extreme season it needs help from the mechanical system of acclimatization and ventilation; the final energy demand is only $3.82 \mathrm{kWh} / \mathrm{m} 2 \mathrm{a}$. Thanks to the attention given during the design process VELUXlab is the first proof of the importance of shadows and overheating prevention in the energy performance, it is the tangible proof that a sustainable building should integrate the 
design, the bio climatic strategies, the services and the control system. The first results about VELUXlab are encouraging about the possibilities of understanding better the interaction between the climate stresses and the building answer. It is clear that the Active House vision is the future of the sustainability in the construction sector: responsive homes, capable to adapt its configuration, its services and the bio climatic strategies according to the weather in an intelligent and smart way.
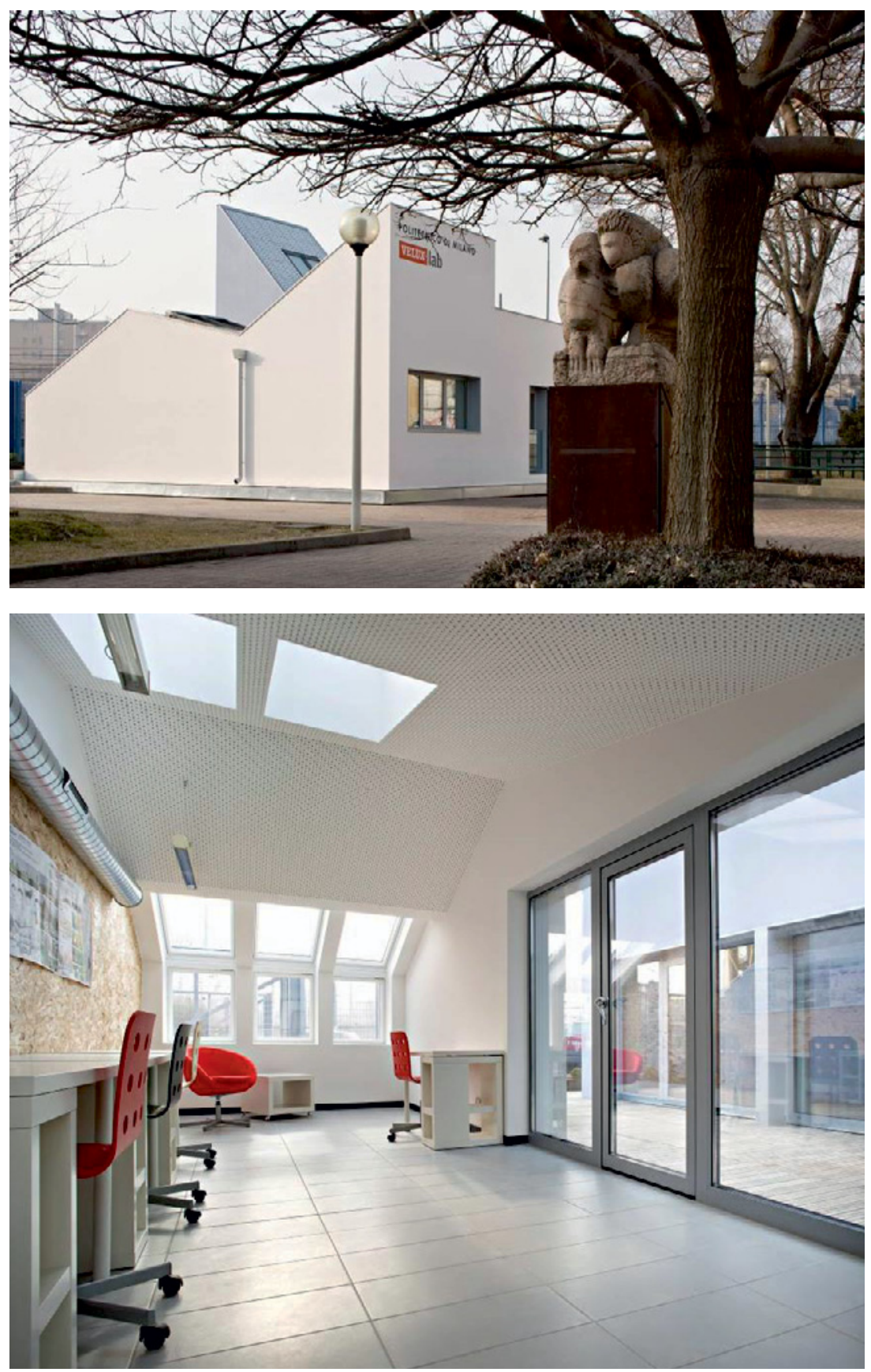

Figure 1. VELUXlab. The shape and the envelope are optimized for Mediterranean climate

Figure 2. VELUXlab. Indoor environment, thermal and lighting comfort are maximized 


\section{References}

1. Active House Alliance - Active House Specification - www.activehouse.com, 2012

2. EPBD recast - Directive 2010/31/EU, Official Journal of the European Union

3. EIA - Annual Energy Review 2004, Energy information administration, 2005

4. Pless, S. and Torcellini, P. - Net Zero Energy Buildings: a classification system based on renewable energy supply options, Technical report for NREL, 2010

5. Voss et al. - From low-energy to net zero-energy buildings: status and perspectives, Journal of Green Building, 2011

6. Torcellini, P.; Deru, M.; Pless, S. and Crawley, D. - Zero Energy Buildings: A critical look at the Definition, ACEE Summer Study, 2006

7. Deru, M. and Torcellini, P. (2006) "Source Energy and Emission Factors for Energy Use in Building” technical report for NREL 